\title{
The effect of wind on the snow cover
}

\author{
Sergey A. Sokratov, ${ }^{1 *}$ Atsushi Sato ${ }^{2}$ \\ ${ }^{1}$ Cooperative Institute for Research in Environmental Sciences (CIRES), University of Colorado, Boulder, CO 80309-0449, U.S.A. \\ ${ }^{2}$ National Research Institute for Earth Science and Disaster Prevention, Shinjo Branch of Snow and Ice Studies, Shinjo, Yamagata 996 -0091 Japan
}

\begin{abstract}
Results of wind-tunnel investigations of the propagation of air within snow showed that the process responsible for causing horizontal air flux in the pore space of snow was not necessarily related to specific surface topography. The reasons for this flux formation are: (i) the near-surface wind characteristics, such as the frequency of the pressure variation related to the turbulent character of the near-surface wind; (ii) the structure of the near-surface snow, responsible for the air exchange between the atmosphere and the pore space; and (iii) the temperature difference between the snow and the atmosphere, forming the air-density difference which augments or decreases the air exchange. This paper summarizes the experimentally observed effects that the wind and the air flux generated in the pore space had on snow. These included isothermal temperature distributions throughout the artificial snow cover, snow-density change and snow recrystallization.
\end{abstract}

\section{INTRODUCTION}

Incorporating the flux of air in the pore space of snow into the description of thermomechanical processes concerns more than just the changes in effective heat conductivity of snow and enhanced water-vapor diffusion in the pore space. In fact, the conclusion that the presence of such air flux should control both the heat and the mass transfer (Yen, 1962, 1963; Albert and McGilvary, 1992) leads us to expect a large influence of wind propagation on other snow phenomena, such as mass exchange with the atmosphere, and snow metamorphism. However, the presence of wind propagation itself has always been questioned. Although models describing the behavior of the air flux in pores were continuously developed (Yosida, 1978a-c; Colbeck, 1989, 1997; Clarke and Waddington, 1991; Albert, 1993), there was limited reported evidence on the process itself (Dubrovin and Petrov, 1964; Oura and others, 1967; Albert and Hardy, 1995). The main goal of the experimental work recently carried out by the authors (Sokratov and Sato, 2000) has been to determine whether propagation of wind indeed exists. It does. As a result, and despite the fact that the work on a physical model of the snowcover-near-surface-wind interaction is still in progress, it is already possible to look for the effects that the air flux in the pore space could have on the various physical processes.

The present paper collects the experimental data from the wind-tunnel experiments of Sokratov and Sato (2000), which were not directly related to modeling the wind--snow interaction. Analysis of these data may be useful for further studies involving wind and snow-cover interaction.

* Also at: Laboratory of Snow Avalanches and Mudflows, Department of Geography, Moscow State University, GSP-3, Vorobievy Gory, 119899 Moscow, Russia.

\section{EXPERIMENTAL PROGEDURE}

A detailed description of the experimental set-up and examples of the results were presented in Sokratov and Sato (2000). The measurements were made in an artificial snow cover of $0.3 \mathrm{~m}$ depth constructed in a wind tunnel with dimensions $1 \mathrm{~m} \times 1 \mathrm{~m} \times 14 \mathrm{~m}$ (Fig. 1). The calculation of the velocity of the horizontal air flux in the pore space was made as follows: a vertical cross-section of the snow cover, perpendicular to the direction of wind produced in the wind tunnel, was maintained at a temperature different from that of the surrounding environment by a temperature regulation in a crooked tube connected to a thermostat. The temperature field around the tube was symmetrical relative to the position of the cross-section ("heat wall") in the snow cover in the absence of wind (Sokratov and Sato, 2000). When the wind was blowing, however, the temperatures measured in the snow at the same depth and the same distance from the "heat wall", but at positions upstream and downstream of the controlled cross-section, were unequal, forming an asymmetrical temperature field. This asymmetry was related to the air flux in the pore space of the snow due to the wind. Based on the change of heat capacity of the air with temperature, and referring to the possible conductive heat flux in the ice matrix

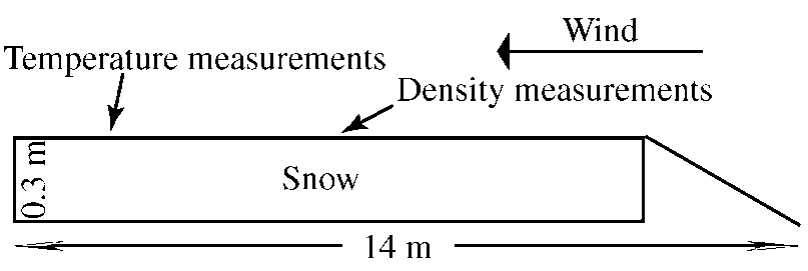

Fig. 1. Schematic representation of the experimental set-up. More details in Sokratov and Sato (2000). 


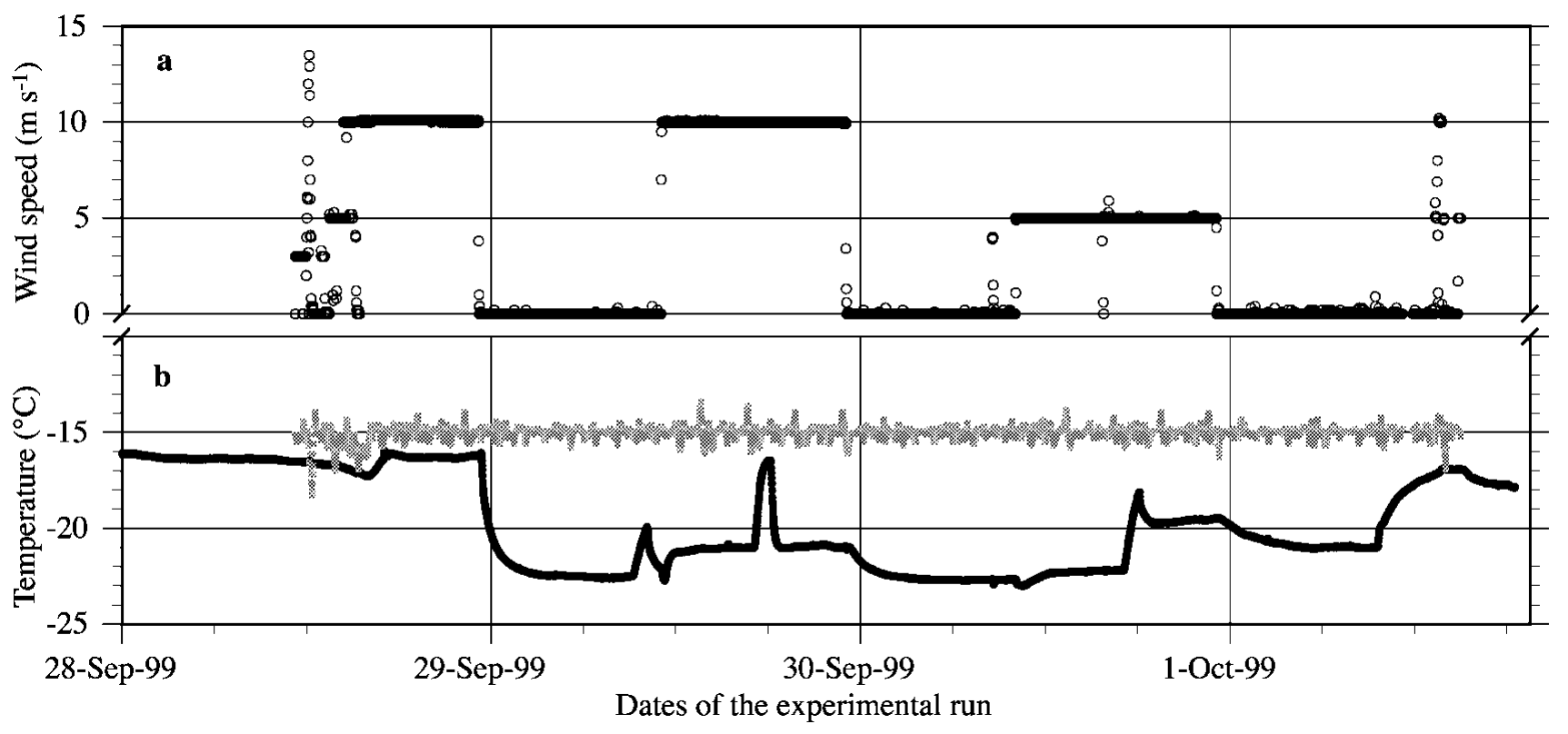

Fig. 2. Example of the experimental data with 1 min time interval between measurements: (a) wind speed during the experimental run; (b) temperature in the wind tunnel obtained by platinum resistance (gray points), and temperature of snow (black points), obtained by one of 60 thermocouples (this was positioned at $0.2 \mathrm{~m}$ depth at the "heat wall").

having opposite directions upstream and downstream of the "heat wall", the temperature data were interpreted as the amount of air flux in the pore space required for the observed degree of non-symmetry.

The calculated horizontal air-flux velocities in the pore space were found to be in agreement with the few previously published results measured by different techniques, and they were close to theoretically possible values. The horizontal air-flux velocities decreased with depth, being approximately 10 times smaller at $0.2 \mathrm{~m}$ depth than in the first few centimeters near the snow surface. At $0.01-0.02 \mathrm{~m}$ depth they were in the range $0.01-0.04 \mathrm{~m} \mathrm{~s}^{-1}$ for near-surface wind speeds of 5-14 $\mathrm{m} \mathrm{s}^{-1}$. The horizontal air-flux velocity increased with an increase of the wind speed.

The data discussed below were obtained in an experimental run, lasting 4 days, with a cold-room temperature of $-15^{\circ} \mathrm{C}$ and a temperature of the crooked tube of $-25^{\circ} \mathrm{C}$. For this experimental run, the artificial snow cover (in the order described below) was twice under the influence of $10 \mathrm{~m} \mathrm{~s}^{-1}$ wind (approximately $24 \mathrm{~h}$ in total) and once under $5 \mathrm{~m} \mathrm{~s}^{-1}$ wind (approximately $12 \mathrm{~h}$ ). Between the "windy" periods there were periods (also about $12 \mathrm{~h}$ each) of "no-wind" conditions (Fig. 2). The short periods of variable wind seen in Figure 2 were related to specific experimental equipment calibration and air-pressure measurements on the snow surface, not discussed in the present paper. The thermostat was switched "on" immediately after the onset of the first $10 \mathrm{~m} \mathrm{~s}^{-1}$ "windy" period, and was only switched "off" at the end of the run, except for short periods (also seen in Fig. 2), when some additional measurements were made in the snow.

\section{EFFEGT OF THE WIND ON THE SNOW DENSITY}

The artificial snow was produced in the Cryospheric Environmental Simulator (Higashiura and others, 1997) and was collected in boxes of size $0.8 \mathrm{~m} \times 0.4 \mathrm{~m} \times 0.3 \mathrm{~m}$ placed on the experimental table in the cold room under the snow machine. After the initial settling, some of the boxes with snow were moved to the wind tunnel, subjected to the wind (the walls with dimensions $0.8 \mathrm{~m} \times 0.3 \mathrm{~m}$ were removed; these faces served as contacting areas between the snow blocks forming the snow cover), and the corresponding experimental measurements were immediately conducted (Sokratov and Sato, 2000). The remaining boxes were left on the table in the cold room for comparison. Figure 3 shows the density profiles observed after the experimental run, for the same initial snow

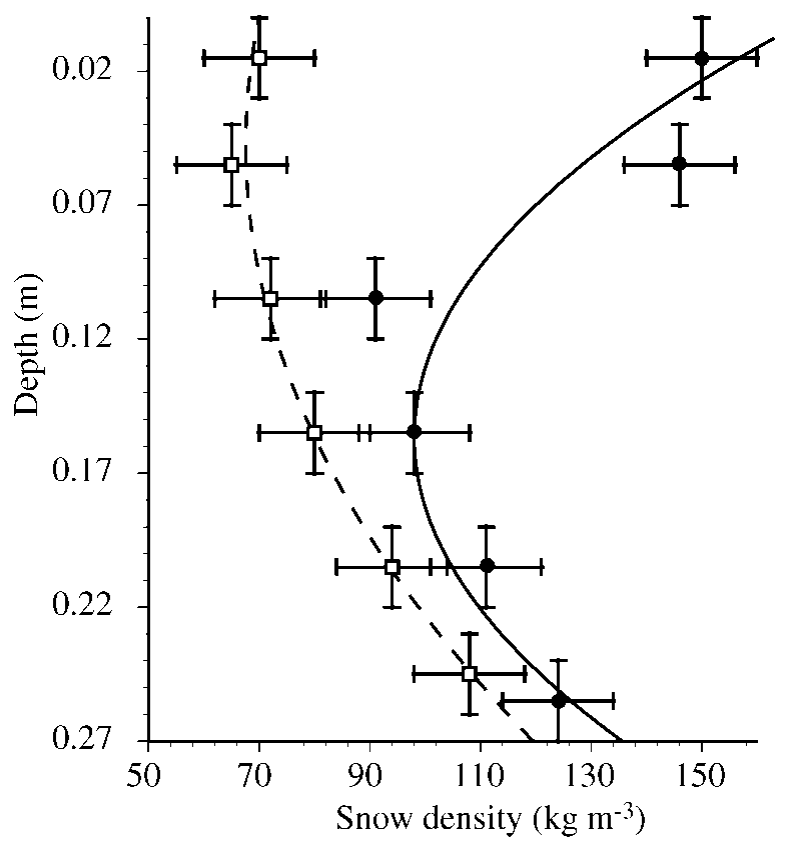

Fig. 3. Densification of snow with wind (solid points approximated by solid line) and without wind (empty squares approximated by dashed line). The vertical bars show positions of density measurements. Horizontal bars are the estimated error bars. The initial snow density corresponds to the upper part of the density profile without wind. The environmental temperature was $-15^{\circ} \mathrm{C}$ for the period of 4 days. For the wind "history"see text and Figure 2. 
and the same temperature regime during the experiment, with one of the boxes in the wind tunnel (solid line) and the other one left in the cold room (dashed line). Throughout the snowpack the initial density was close to that in the upper part of the snow left on the table. Snow densities near the bottom of the boxes were very close to each other and represented the "gravitational" densification. The upper part of the snow from the wind tunnel, however, shows approximately the same densification rate as near the bottom. This densification can only be explained by a force, vertically applied to the snow surface. This force had to be a result of the turbulent character of the near-surface wind in the wind tunnel.

Such density profiles lead us to conclude that in the equations of snow densification (Guseva-Lozinski, 1997), dependent on the type of snow and its mechanical properties, the influence of the mechanical wind pressure must be considered only for the near-surface part of the snowpack, and can be excluded from considerations below a certain depth. For the snow used in the present experiments, this depth was approximately $0.07 \mathrm{~m}$.

The density results strongly support the idea that the "fluctuation pressure", i.e. high-frequency vertical pressure fluctuations at the snow-cover surface caused by turbulence, acts as the dominant driving force for the air flux in the pore space (Yosida, 1977). Accepting this also allows us to divide the air flux in the pore space, as suggested by Yosida (1977), into the horizontal "steady internal flow" at depth, represented for the conditions of our experiments by the measured horizontal air-flux velocities of $0.01-0.04 \mathrm{~m} \mathrm{~s}^{-1}$ (Sokratov and Sato, 2000), and the three-dimensional "fluctuating internal flow" close to the surface, having ten times higher "non-directional" air-flux velocities for similar wind speeds (Öura and others, 1967). This fluctuating internal flow almost disappears at about $0.07 \mathrm{~m}$ depth for low-density snow like that used in our experiments.

The mechanical wind pressure in this case must be considered both on the snow surface as well as within the near-surface snow layer. This involves the characteristics of the nearsurface wind turbulence that is responsible for the fluctuation pressure over the snow surface and the turbulence inside this snow layer. However, as both processes correlate with the wind speed over the snow surface, the surface snow density should be higher at higher wind speeds, as reported from field observations (Lipenkov and others, 1998).

\section{EFFECT OF WIND ON SNOW METAMORPHISM}

It was not possible to make a detailed estimation of the snowrecrystallization rate for the experiments reported in Sokratov and Sato (2000). This failure was due not only to technical problems, but also to the change of snow type during the experimental run. The initial snow consisted of crystals similar to "precipitation particles" in the form of "stellar dendrites" (Colbeck and others, 1990). The recrystallization did not proceed further than to the "rounded grains" of "mixed forms" in the snow left on the table. However, in the wind tunnel the surface of the artificial snow cover was represented by up to $1 \times 10^{-3} \mathrm{~m}$ size "faceted crystals" of "solid faceted" and "mixed" forms (Colbeck and others, 1990).

In the snow crystals of the cross-section where temperature measurements were taken (Sokratov and Sato, 2000), the temperature underwent a gradual change from $-15^{\circ}$ to $-25^{\circ} \mathrm{C}$ (Fig. 2). The crystals were under the influence of both

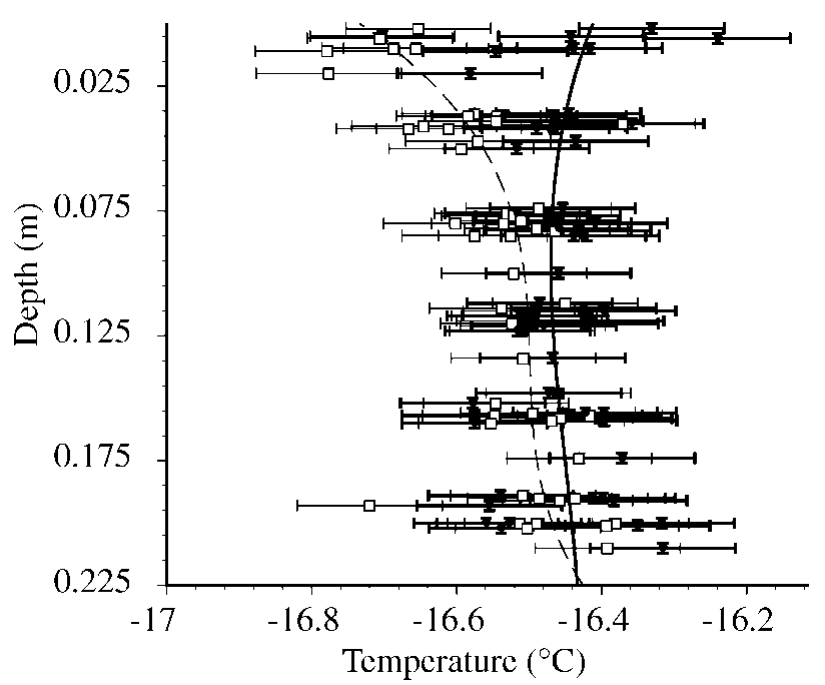

Fig. 4. "Isothermal" temperature distributions throughout the artificial snow cover with $10 \mathrm{~m} \mathrm{~s}^{-1}$ wind (solid points approximated by solid line) and without wind (empty squares approximated by dashed line), measured by 60 thermocouples. The horizontal bars show the temperature varying during a corresponding period of measurement in each position of the measurements. The vertical bars correspond to possible inaccuracy of the determination of the depth. The snow density had to be in between the profiles shown in Figure 3.

a temperature gradient and the horizontal air flux in the pore space. However, comparing this snow with the recrystallization of similar snow subjected to much higher temperature gradients without induced air flux (Kamata and others, 1999) led us to conclude that the influence of the air flux prevailed. Among faceted crystals, large amounts of needles were found after the experimental run. The needles even formed several regions with "needles only" in between some thermocouples, where the gravitational snow densification could be suppressed because these thermocouples supported overlying snow layers.

Such needle formation is evidence of the possibility of the total renewal of the snow crystals in a very short period of time when air flux is present, at least when the ice matrix is $5-10^{\circ} \mathrm{C}$ colder than the atmosphere. The needles, shown in the "growth-habit graphs" illustrating ice nucleation from the vapor phase (Hobbs, 1974, see figs 8.4, 8.7, 8.12, 10.11), were observed under much higher temperatures than those in the present experiments. Thus, the results of our observations indicate that the temperatures of the air flux in the pore space around the crooked tube were either only slightly lower than the temperature of the cold room, with still $>150 \%$ water-vapor saturation rate, or corresponded to even higher water-vapor supersaturation relative to the temperature of the ice matrix. In any case, such temperature-supersaturation ranges were not studied for the construction of the "growth habit graphs" published so far.

\section{EFFEGT OF THE WIND ON THE TEMPERATURE DISTRIBUTION}

It is known that the temperature of an evaporating surface may be lower than the bulk temperature and the temperature of the environment (Golubev and Sokratov, 1991). This effect is related to latent-heat losses. In relation to an ice surface, these heat losses show a clear dependence on the wind 


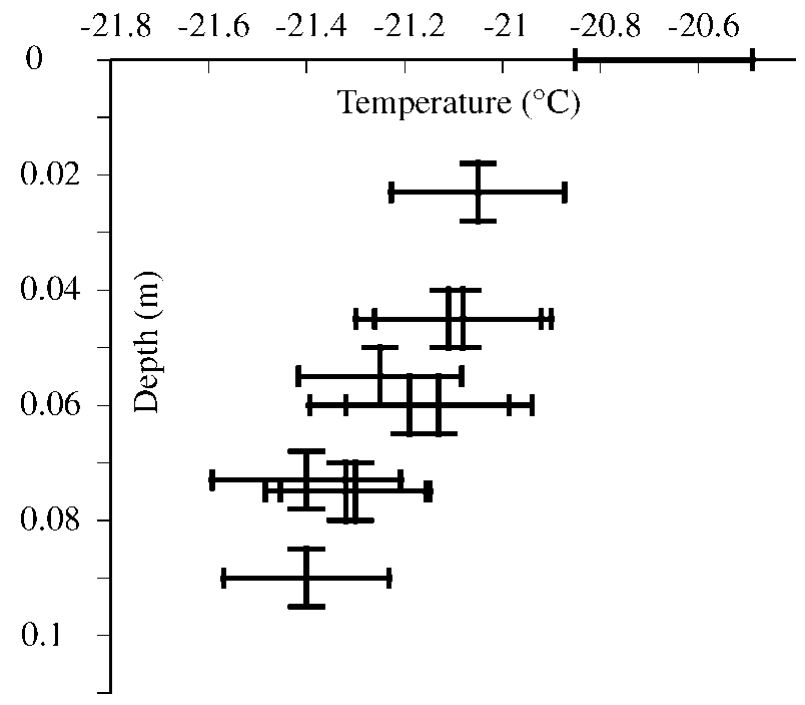

Fig. 5. "Isothermal" temperature distribution in $0.11 \mathrm{~m}$ depth snow layer under $14 \mathrm{~m} \mathrm{~s}^{-1}$ wind over the snow surface. The bars have the same meanings as in Figure 4. The snow density in this case was $\approx 250 \mathrm{~kg} \mathrm{~m}^{-3}$.

speed (Tokairin and Wakahama, 1975). The same behavior was expected in the present experiments. The data shown in Figures 4 and 5 were obtained for so-called isothermal conditions. The temperature data from the cross-section of temperature measurements indeed show that the temperature near the snow surface when snow was not cooled by the thermostat is about $0.3^{\circ} \mathrm{C}$ colder than at depth under conditions without wind (Fig. 4). However, when wind was present, instead of excess surface cooling due to enhanced evaporation, the temperature distribution became more uniform than without wind. This can only be related to a compensation of the heat losses from evaporation by the heat transported in the near-surface wind and in the air flux in the pore space of snow, at least for wind speeds of $5 \mathrm{~m} \mathrm{~s}^{-1}$ and higher. If both the steady and the fluctuating internal flows are present, the heat transported by air suffices to compensate almost any latent-heat losses due to evaporation. However, it can be expected that when a snow cover has a temperature different from that in the atmosphere, the difference will not only change the air flux in the pore space of the snow, as discussed in Sokratov and Sato (2000), but will also change the amount of evaporation from the snow cover. It is expected that a warmer air flux will suppress evaporation or will even lead to condensation. Depending on the air-flux velocity, this may occur with or without a change in the ice-matrix temperature corresponding to the mass- and heat-exchange process. Cold air flux can greatly increase the evaporation rate, again with or without compensation of the evaporating cooling. For high-speed winds $\left(14 \mathrm{~m} \mathrm{~s}^{-1}\right)$, the air flux was actually cooling the snow at some depth; this is illustrated by data shown in Figure 5, where the air flux in the pore space involved the "deep" ice matrix in the process of evaporation, but heat transported by wind kept the surface temperature the same as the ambient temperature.

The amount of evaporation/condensation is directly linked to the recrystallization rate (Sokratov and others, 2001). Based on that, only the presence of a relatively warm wind over a snow surface, with a wind speed less than some limiting value ( $\approx 2 \mathrm{~m} \mathrm{~s}^{-1}$, according to Hachikubo and Akitaya (1997), for the conditions of their investigations), should lead to an extremely high rate of recrystallization of the surface crystals. If the wind speed is too large, the ice-matrix temperature will increase, which decreases the condensation rate. Such considerations should be taken into account in explanations of the surfacehoar formation reported in several publications (e.g. Steffen and others, 1999; Fahnestock and others, 2000).

\section{GONGLUSIONS}

Analysis of the experimental wind-tunnel results allows isolation of the following effects, related to the process of wind propagation into snow:

near-surface densification of snow is caused by fluctuations of the air pressure on the surface, and related to the turbulent character of the near-surface wind;

enhanced snow recrystallization occurs and is related to the presence of the air flux in the pore space, and especially to the possibility of a temperature difference between the ice matrix and the pore air flux;

there is an influence of the wind and the corresponding air flux in the pore space on the amount of evaporating/ condensing material, both on the surface and at some depth. On the one hand, the air flux activates the mass exchange between the ice matrix and the air in the pores; on the other hand, it compensates or enhances the temperature change related to the latent-heat release.

The present experimental data showed only part of the effects of the wind propagation on the evolution of the snow cover. At the present stage of interpretation, the complexity of the air flux in the pore-space interaction with the ice matrix did not allow us to make a numerical estimation of the effects listed above. However, the data presented at least provide ranges of possible thermal and mechanical processes, when there is wind blowing over the snow surface. Thus, they can be used as a basis for further theoretical and experimental investigations on wind propagation into the snow cover.

\section{ACKNOWLEDGEMENTS}

The preparation of this paper and the Conference presentation was supported by the award of a Visiting Fellowship at CIRES, University of Colorado, Boulder, to S. A. Sokratov. The experimental data used were obtained with partial support of the Japan Science and Technology Agency through JSTandJISTEC (S. A. Sokratov). The authors are grateful to K. Hutter and R.G. Barry for useful suggestions on data presentation and editing the paper.

\section{REFERENGES}

Albert, M. R. 1993. Some numerical experiments on firn ventilation with heat transfer. Ann. Glaciol., 18, 161-165.

Albert, M. R. and J. P. Hardy. 1995. Ventilation experiments in a seasonal snow cover. International Association of Hydrological Sciences Publication 228 (Symposium at Boulder 1995 - Biogeochemistry of Seasonally Snow-Covered Catchments), 41-49.

Albert, M. R. and W. R. McGilvary. 1992. Thermal effects due to air flow and vapor transport in dry snow. F. Glaciol., 38(129), 273-281.

Clarke, G. K. C. and E. D. Waddington. 1991. A three-dimensional theory of wind pumping. F. Glaciol., 37(125), 89-96.

Colbeck, S. C. 1989. Air movement in snow due to windpumping. F. Glaciol., 35(120), 209-213.

Colbeck, S. C. 1997. A model of wind pumping for layered snow. F. Glaciol., 43(143), 60-65. 
Colbeck, S. C. and 7 others. 1990. The international classification for seasonal snow on the ground. Wallingford, Oxon, International Association of Scientific Hydrology. International Commission on Snow and Ice.

Dubrovin, L. I. and V. N. Petrov. 1964. Thermal effects of air currents on thermometers measuring the temperature of snow and firn in a borehole [Teplovoye vozdeystviye vozdushnogo potoka na termometry, izmeryayushchiye temperatury snezhno-firnovoy tolshchi v skvazhine]. Sov. Antarct. Exped. Inf. Bull., 5(4), 266-268.

Fahnestock, M. A., T. A. Scambos, C. A. Shuman, R. J. Arthern, D. P. Winebrenner and R. Kwok. 2000. Snow megadune fields on the East Antarctic Plateau: extreme atmosphere-ice interaction. Geophys. Res. Lett., 27(22), 3719-3722.

Golubev, V. N. and S. A. Sokratov. 1991. Isparenie snega v izotermicheskikh usloviiakh [Evaporation of snow under isothermal conditions]. Mater. Glyatsiol. Issled. 71, 27-32.

Guseva-Lozinski, E. 1997. Mathematical modeling of temporal changes in snow-firn properties in the cold season. Ann. Glaciol., 24, 309-313.

Hachikubo, A. and E. Akitaya. 1997. Effect of wind on surface hoar growth on snow. 7. Geophys. Res., 102(D4), 4367-4373.

Higashiura, M. and 6 others. 1997. Preparation of the experimental building for snow and ice disaster prevention. In Izumi, M., T. Nakamura and R. L. Sack, eds. Snow engineering: recent advances. Rotterdam, A. A. Balkema, 605-608.

Hobbs, P.V. 1974. Ice physics. Oxford, Clarendon Press.

Kamata, Y., S. A. Sokratov and A. Sato. 1999. Temperature and temperature gradient dependence of snow recrystallization in depth hoar snow. In Hutter, K., Y. Wang and H. Beer, eds. Advances in cold-region thermal engineering and sciences: technological, environmental, and climatological impact. Berlin, etc., Springer-Verlag, 395-402. (Lecture Notes in Physics 533.)

Lipenkov, V.Ya., A. A. Yekaykin, N. I. Barkov and M. Purshe. 1998. O svyazi plotnosti poverkhnostnogo sloya snega v Antarktide so skorost'yu vetra [On the connection between density of surface ice layer in Antarctica with wind velocity]. Mater. Glyatsiol. Issled. 85, 148-158.

Ōura, H., T. Ishida, D. Kobayashi, S. Kobayashi and T. Yamada. 1967. Studies on blowing snow II. In Öura, H., ed. Physics of snow and ice. Vol. 1, Part 2. Sapporo, Hokkaido University. Institute of Low Temperature Science, 1099-1117.

Sokratov, S. A. and A. Sato. 2000. Wind propagation to snow observed in laboratory. Ann. Glaciol., 31, 427-433.

Sokratov, S. A., Y. Kamata and A. Sato. 2001. Water-vapor flux appearance in snow. Ann. Glaciol., 32 (see paper in this volume).

Steffen, K., W. Abdalati and I. Sherjal. 1999. Faceted crystal formation in the northeast Greenland low-accumulation region. F. Glaciol., 45(149), 63-68.

Tokairin, A. and G. Wakahama. 1975. [Measurements of the sublimationevaporation rate of ice and the total heat loss from the ice surface under various wind speeds.] Low Temp. Sci., Ser. A 33, Data Report, 7-16. [In Japanese.]

Yen, Y.-C. 1962. Effective thermal conductivity of ventilated snow. 7. Geophys. Res., 67 (3), 1091-1098.

Yen, Y.-C. 1963. Heat transfer by vapor transfer in ventilated snow. F. Geophys. Res., 68(4), 1093-1101.

Yosida, Z. 1977. [Air flow induced in a snow cover by the wind blowing over its surface.] Low Temp. Sci., Ser. A 35, 47-65. [In Japanese with English summary.]

Yosida, Z. 1978a. [Theoretical studies on air flow within snow. I. Equations of motion.] Low Temp. Sci., Ser. A 36, 11-27. [In Japanese with English summary.]

Yosida, Z. 1978b. [Theoretical studies on air flow within snow. II. Boundary conditions at a porous surface when fluid flows over it in the form of laminar flow.] Low Temp. Sci., Ser. A 36, 29-40. [InJapanese with English summary.]

Yosida, Z. 1978c. [Theoretical studies on air flow within snow. III. Flow of fluid in the surface transition layer.] Low Temp. Sci., Ser. A 36, 41-54. [In Japanese with English summary.] 